\title{
A career success model for academics at Malaysian research universities
}

\begin{abstract}
Purpose - The purpose of this paper is to develop a career success model for academics at the Malaysian research universities.

Design/methodology/approach - Self-administered and online surveys were used for data collection among 325 academics from Malaysian research universities.

Findings - Based on the analysis of structural equation modeling, the proposed model explained 48 percent of the variance of academics' career success. Specifically, the result shows that there are positive significant effects between organizational support, extraversion personality, person-job fit and academics' career success. A full mediation effect of proactive behavior was established on the relationship between organizational support and career success. Overall, the results confirmed that the proposed model succinctly explains career success among academics in Malaysian research universities.

Research limitations/implications - The authors present a career success model for academics at Malaysian research universities. The study represents an important extension of previous research of which it tested the applicability of the career success theories and identified the key factors related to career success of academics based on the context of Malaysian research universities. Most current career success studies were conducted in the context of the Western culture or developed countries; therefore, the results based on the Malaysian sample provide strong evidence of cross-cultural comparability of the career success construct and model.

Practical implications - The findings provide implications to both individuals and human resource development practitioners on career success among academics. Practical interventions are suggested to assist individuals and organizations toward achieving career success. This study sheds some light on the effective management of the academics.

Originality/value - The authors propose a model of academics' career success based on the context of Malaysian research universities.
\end{abstract}

Keyword: Proactive behaviour; Career success; Career; Extrinsic career success; Intrinsic career success; Research university 